\title{
Physics teacher isolation, contextual characteristics, and student performance
}

\author{
Robert Krakehlø \\ Institute for STEM Education, Stony Brook University, 092 Life Sciences, Stony Brook, \\ New York 11794-5233, USA \\ and Manhasset High School, 200 Memorial Place, Manhasset, New York 11030, USA \\ Angela M. Kelly ${ }^{*}$ \\ Department of Physics \& Astronomy and Institute for STEM Education, Stony Brook University, \\ 092 Life Sciences, Stony Brook, New York 11794-5233, USA \\ Keith Sheppard® \\ Department of Biochemistry \& Cell Biology and Institute for STEM Education, Stony Brook University, \\ 092 Life Sciences, Stony Brook, New York 11794-5233, USA \\ Martin Palermo $\odot$ \\ Institute for STEM Education, Stony Brook University, 092 Life Sciences, Stony Brook, \\ New York 11794-5233, USA \\ and William Floyd High School, 240 Mastic Beach Road, Mastic Beach, New York 11951, USA
}

(Received 22 May 2020; accepted 24 July 2020; published 28 August 2020)

Physics, as a foundational science, has particular importance in predicting the postsecondary success of students who major in science, technology, engineering, and mathematics. This quasiexperimental, observational study examined teacher-level and school-level predictors of student performance in physics, with a focus on isolated teachers. A New York State case study is useful since the teacher certification policy is largely determined at the state level in the U.S. The overall sample included New York State public schools that offered physics $(N=960)$, physics teachers $(N=1584)$, and student physics test takers $(N=47734)$ in the academic year 2016-2017. Teacher-level variables included the content preparation and certification of physics teachers, physics course load, professional age (years of experience), whether the teacher was isolated, whether the teacher taught mathematics, and whether the teacher taught Advanced Placement Physics; and school-level variables including physics standardized test passing rates, school size, socioeconomic status, locale, and physics course taking ratio. Data were collected from a variety of publicly available sources that were verified by state education agencies. Results indicated a significant proportion (40\%) of physics teachers were isolated, and their students tended to have weaker physics performance scores than students of nonisolated teachers. Compared to the nonisolated teachers, a larger percentage of isolated physics teachers were uncertified in physics and taught in urban and rural schools. There was no significant difference in professional age between isolated and nonisolated teachers, but urban teachers had less teaching experience than suburban and rural physics teachers. When analyzing the subset of isolated teachers $(n=449)$, a multiple linear regression model indicated urban locale and schoollevel socioeconomic status were the main negative predictors of student physics performance, while rural physics locale and professional age were positive predictors of physics performance; the model explained $38 \%$ of the variance, a large effect. Teaching experience acted as a mediator of poverty and urban locale in predicting student physics performance with a small effect size. Implications related to equity considerations and physics education policy are discussed.

DOI: 10.1103/PhysRevPhysEducRes.16.020117

\footnotetext{
*angela.kelly@stonybrook.edu
}

Published by the American Physical Society under the terms of the Creative Commons Attribution 4.0 International license. Further distribution of this work must maintain attribution to the author(s) and the published article's title, journal citation, and DOI.

\section{INTRODUCTION}

\section{A. High school physics access and course taking}

Precollege physics has been identified as an important gateway course for post-secondary science, technology, engineering, and mathematics (STEM) study and performance, as it is regarded a foundational science that 
contributes to overall science literacy and preparedness [1-3]. Research has shown that students who took more advanced science courses in high school were more likely to attain a STEM degree in college [4]. Students who took a quantitative physics course during high school earned a STEM degree at a rate of approximately $18.7 \%$, nearly twice as often as those whose most advanced science was chemistry, receiving a STEM degree at a rate of only $8.8 \%$ [2]. Students who enrolled in one or two years of physics in high school have also demonstrated significantly higher STEM career interest and attainment, as opposed to those who only took a second course in a science other than chemistry [5].

Although the importance of high school physics course taking has been well established, contextual factors that have influenced physics accessibility, participation, and performance have received less attention in prior research. Over the past thirty years, there has been continued growth in the number of physics courses offered in addition to an increase in the number of students taking physics. The American Institute of Physics (AIP) estimated that 39\% of high school students completed a physics course before graduating in 2013 [6]. However, physics participation has varied by ethnicity and socioeconomic status. The proportion of Black and Latino students enrolling in high school physics in 2013 was less than $30 \%$ [7]. According to the National Science Board, students in the lowest socioeconomic status quintile were less likely to take a physics course than students in the highest quintile (32\% vs $56 \%$, respectively) [8].

Several studies have indicated that access to physics courses is inequitable when considering race and class [9-12]. The U.S. Department of Education reported that physics was offered in $60 \%$ of all U.S. high schools in $2015-16$, yet available in only $51 \%$ of high schools with high Black and Latino enrollment [13]. Similar disparities exist for low socioeconomic schools, where physics overall and Advanced Placement Physics have been offered less frequently than in better off schools $[9,14]$. These data suggest that exploring physics accessibility and performance across contextual factors may provide insights on more equitable physics teaching and learning in U.S. high schools.

\section{B. Physics teacher qualifications and course load}

While physics access and enrollments are important factors in increasing student preparedness for postsecondary STEM study, the prevalence of underqualified teachers in the physical sciences is also a concern [15-17]. Darling-Hammond [18] identified teacher-level factors that impact student performance in STEM, including degree in the field taught, certification status, teaching experience, and subject matter knowledge. AIP defined a physics specialist as a teacher who earned a degree in physics or physics education, had at least five years of high school teaching experience, taught physics for at least half of their teaching career, and was teaching physics at the time of the AIP 2012 survey. Just $60 \%$ of physics teachers reported themselves as physics specialists in 2012-13, with the other $40 \%$ reporting they primarily taught courses in other disciplines [12]. The average percentage of physics courses taught in a physics teachers course load increased from $44 \%$ to $60 \%$ from 1993 to 2013 . However, it has been estimated that only $40 \%$ of physics teachers held a degree in either physics or physics education, suggesting $60 \%$ of physics teachers had only a basic level of physics knowledge and pedagogical expertise [19].

A recent longitudinal study indicated that nearly $50 \%$ of physics teachers who took the Praxis exam in 40 states held a certification within physics (in-field), $40 \%$ held a certification in teaching but not in physics (out of field), and $10 \%$ held a nonregular certification or no certification in teaching (out of field) [16]. However, several heavily populated states did not require the Praxis exam (e.g., Texas, Florida, California, and New York) so many physics teachers were left out of the sample.

\section{Physics teacher isolation}

Physics is set apart from other STEM disciplines for several reasons, one being the frequent isolation of physics teachers. Isolation can be defined as a practitioner being the only physics teacher within a particular school. Nearly $80 \%$ of high schools that offered physics in 2008-09 had only one physics teacher [20]. This implies that many newly hired physics teachers do not have access to a mentor in the same subject in the same school. Although electronic social networks have alleviated some of the issues associated with physics teacher isolation, only $17 \%$ of isolated teachers felt they had adequate opportunities to collaborate with other physics teachers. Isolated physics teachers have been less likely to join professional organizations than teachers who work in high schools with more than one physics teacher [20].

Additionally, physics teachers often do not exclusively teach physics due to relatively low enrollment in physics courses [19]. In a study of isolated chemistry teachers, data revealed that these teachers were less experienced, less likely to be certified in chemistry, and more likely to work in high needs schools [15]. Novice teachers in the subjects of physics, chemistry, physical science, geometry, and biology displayed an improvement in their teaching effectiveness with more years of teaching experience [21]. Research has suggested that professional isolation among teachers may relate to increased occupational stress, perceptions of inadequate administrative support, and teacher attrition [22-24].

\section{State-level case study rationale}

A common limitation among research studies in physics teacher preparation, school characteristics, and student 
performance is the lack of contextual specificity. Studies have often been conducted using data from national datasets or self-reported survey data (for example, Refs. [12,16,19, 20]). These studies also tend to have an "averaging effect" which often mask widespread variations among different states. The U.S. educational system is somewhat disjointed given educational policies are most often dictated at the state, county, and district levels. Decentralized school governance is often more responsive to community needs and fiscal accountability, however, this often results in variations in curricula [25]. There is a need for state-level case studies in order to understand localized contextual factors and their interplay with state policies and student performance. Data for these are now much more readily available at the state level as a result of the accountability requirements of the $N o$ Child Left Behind legislation in 2002.

A persistent state-level issue is the lack of qualified teacher supply, and states establish their own licensure requirements [26,27]. Science teachers leave the field at relatively high rates, particularly novice teachers [27,28]. Strengthening teacher retention in STEM fields is vital as it helps reduce teacher shortages and retain more qualified teachers [29]. In response to the chronic shortage of physics teachers, states may set different requirements for certification. While teachers may be considered to be qualified in some states, the same teachers may be considered unqualified in other states, removing the generalizability of research findings and subsequently masking the wide variations among states [15].

\section{E. Research questions}

The present study examined several issues related to high school physics, specifically, teacher-level and school-level variables that may influence physics accessibility, participation, and performance. The research questions included the following:

1. What is the extent of professional isolation of New York State physics teachers?

2. How do physics performance and contextual characteristics compare in high schools with isolated teachers vs schools with multiple physics faculty?

3. When considering school contexts, how are physics availability, physics course taking, and the course load of physics teachers differentiated?

4. When examining the students of isolated physics teachers, what school and teacher characteristics predict and mediate physics performance?

\section{THEORETICAL FRAMEWORK}

The framework for this study was a composite of theoretical constructs related to (i) workplace tensions for physics teachers, and (ii) equity concerns for physics students. In exploring physics accessibility, course taking, and performance on a statewide scale, it was hypothesized that contextual disparities would be evident. Consequently, school-level, teacher, and student factors that may have contributed to inequitable physics performance were identified based on recent literature.

\section{A. Workplace tensions for teachers}

Physics teachers have often experienced workplace tensions associated with several contextual constraints, including isolation, teaching out of field, and turnover. The pervasive nature of professional isolation for physics teachers, evidenced by the average $80 \%$ of U.S. high schools that employed a single physics teacher [20], may result in stressful working conditions associated with pedagogical content knowledge development and sense of inadequacy [22,23]. The high occurrence of out-of-field teaching in physics [19] suggests that isolation may be further exacerbated by a lack of mentoring and peer coaching that is more commonly experienced by teachers in schools with multiple physics specialists. Frequent socialization with other domain specialists often provides the motivation and resources for advanced development of subject matter expertise [30].

Since physics enrollments have increased over the past 30 years, and physics teachers have retired faster than new physics teacher graduates could replace them, there has been a persistent shortage of physics teachers in many states [31-33]. Also, the physics teachers have, on average, fewer years of teaching experience [16]. Consequently, physical science teaching positions have often been filled by teachers with primary certifications in other STEM disciplines [17]. The question of whether these workplace tensions relate to students' physics performance is an important issue when considering how education reforms might improve STEM performance and career participation in the U.S.

\section{B. Equity concerns for students}

Students have often experienced inequitable conditions when considering their participation and performance in physics, including concerns related to physics accessibility, resource allocation, and school-level poverty.

The estimates for physics course availability in the U.S. was $60 \%$ of all schools [13], however, this figure varies widely from state to state [34] and by socioeconomic factors. High poverty schools with large numbers of students traditionally underrepresented in STEM have been less likely to offer physics courses [9,13,14]. Factors contributing to this disparity have often been tied to resource allocation, such as the availability of laboratory materials, counselors recommending physics course taking, and mathematics remediation for low performing students [35]. Pressures associated with standardized testing have also been linked to limited instructional time and inadequate access to physics courses, particularly in high need schools $[20,23,35]$. 


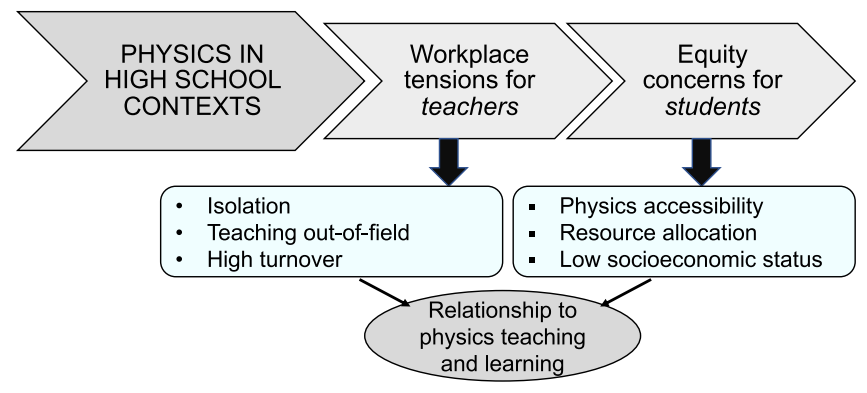

FIG. 1. Theoretical considerations for examining the challenges of teaching and learning physics in high school contexts.

The role of these equity concerns in physics teaching and learning is a critical issue to examine in targeting reform efforts towards students and teachers in specific contexts. High school, undergraduate, and graduate physics programs, as well as STEM careers, are all characterized by a disproportionately low representation of students of color [7,36-39]. In precollege settings, these traditionally underrepresented students in STEM comprise a disproportionately high percentage of students attending high need schools [40]. This necessitates a careful examination of the role of poverty in predicting student performance when combined with other correlating factors.

The theoretical framework for the present study is represented in Fig. 1.

\section{DESIGN}

The present study employed a quasiexperimental, correlational design [41] in examining data from New York State public schools $(N=960)$, physics teachers $(N=1584)$, and student performance as measured by a standardized high-stakes physics examination $(N=47734)$. This was a census study of public-school physics teachers in New York State in the academic year 2016-17. Data used in the study were not self-reported but were taken from publicly available and verified state databases. The purpose of this study was to explore the extent of physics course taking and physics teacher isolation, and identify how student performance in physics differed based on a school's contextual variables as well as teacher-level variables.

\section{A. Context}

According the New York State Education Department, during the 2016-17 school year there were 2629970 students enrolled in the $\mathrm{K}-12$ public school system. Of all students in $\mathrm{K}-12,44 \%$ of all students were White, $26 \%$ were Hispanic or Latino, $17 \%$ were Black or African American, 9\% were Asian or Native Hawaiian/Other Pacific Islander, $2 \%$ were Multiracial, and $1 \%$ were American Indian or Alaskan Native. Additionally, 9\% of all students were English language learners, 17\% had disabilities, and $55 \%$ were economically disadvantaged [42].

In terms of science, students in New York State tended to perform at a higher level on the ACT Science examination when compared to national data (54\% reaching college readiness benchmark vs 39\%), indicating somewhat greater preparation for success in post-secondary science coursework [43]. Students in the state were required to take biology (known as living environment) before graduating, along with one credit in a physical science, which could be earth science, chemistry, or physics [44]. In the 2016-17 academic year, statewide testing data indicated 241338 students took the living environment exam, 154042 took earth science, 105639 took chemistry, and 47905 took physics. These annual course taking patterns were typical in the state [45].

\section{B. Data collection}

Several New York State Education Department data sources were utilized to identify high schools that offered physics, school characteristics, and student performance during the 2016-17 academic year (Table I). Sources included the Basic Education Data System; New York State Report Cards, where data were reported for the state as a whole, and for each county, district, and school [45]; and the New York Teacher Certification Database [46]. All data were publicly available, and cross verified among the schools and the state. Additionally, the Common Core of Data was used for the locale designation for each school [47].

\section{Operational variables}

The operational variables in the present study included several school-level and teacher-level characteristics. The dependent variable was schoolwide physics performance; this variable was reported in aggregate since individual scores were not made available by the state. School-level independent variables included socioeconomic status, school locale (urban, suburban, rural), physics test-taking ratio, school enrollment, and types of physics courses offered. Teacher-level variables included whether or not the teacher was isolated, certification status, professional age (years of experience), and several aspects related to physics teaching load. These variables are described in detail below.

\section{Physics performance}

In the present study, student performance was based upon the results of the statewide standardized examination in physics. The college-preparatory physics course, known as Regents Physics, followed the state mandated Physical Setting/Core Curriculum in Physics, which surveyed the major areas of physics including mechanics, electricity, magnetism, optics, and modern physics. Students were 
TABLE I. Data sources.

\begin{tabular}{lr}
\hline \hline Data source & Information provided \\
\hline $\begin{array}{l}\text { Basic Education Data System } \\
(\text { BEDS })^{*}\end{array}$ & $\begin{array}{r}\text { List of physics teachers, their schools, types of physics courses taught (College Prep, } \\
\text { AP B, AP C Mechanics, AP C Electricity \& Magnetism, or Other), types of science } \\
\text { and mathematics courses taught (Biology, Earth Science, Algebra 1, etc.), number of } \\
\text { students enrolled in each courses, number of sections of each course taught. }\end{array}$ \\
$\begin{array}{l}\text { New York State School District } \\
\text { Report Card }\end{array}$ & $\begin{array}{l}\text { Student population (grades 9-12) in schools where physics was taught. Number of } \\
\text { students tested on the standardized physics exam and passing rate per school. Free }\end{array}$ \\
and reduced lunch percentages. \\
Teacher Certification Database \\
Common Core of Data
\end{tabular}

*BEDS data were collected in October in the beginning of the 2016-17 academic year. Students may have dropped the course, teachers may have gone on leave, etc.

required to complete a minimum of 1200 min of hands-on laboratory work prior to taking the examination [48]. Examination grades were based upon a scale that converted students' raw scores to a grade between 0 and 100. To pass the examination, students needed to earn a scaled score of 65 or higher. In the present study, the performance of students in physics was based upon the percentage of students who earned a scaled score of 65 or higher in a particular school.

\section{School-level variables}

Socioeconomic status was based on the percentage of students within a school who qualified free and/or reduced lunch according to federally designated criteria [49]. School size was based upon the number of students enrolled in grades 9-12. Physics test-taking ratio indicated the percentage of students taking the high stakes physics examination in grades 9-12 as a proportion of the school's population in those grades. This was used as an indication of the prevalence of physics course taking within the school. School locale was defined as urban, suburban, or rural; these designations were based upon population density, distance from metropolitan centers, and needs to resource capacity, as determined by the U.S. Department of Education [47].

\section{Physics course type}

During the 2016-17 school year, there were 1257 high schools and 960 (76.4\%) that offered at least one type of physics course (college-prep, Advanced Placement, and other physics.) The BEDS database listed five unique stand-alone physics courses and did not include courses in physical science [45]. The most commonly taught course was the standardized college-preparatory physics.

The Other Physics category encompassed all courses that did not fit into the five other physics course codes. It often includes courses such as SAT II physics, International Baccalaureate (IB) physics, applied physics, or conceptual physics courses. This category did not have standardized curricula.

Advanced Placement (AP) Physics $B$ was the third category. As of 2014, this course was modified into two distinct courses-AP Physics 1 and AP Physics 2-however, schools could only report it as AP Physics B in 201617. AP Physics B, as well as AP Physics 1 and 2, were equivalent to an algebraic introductory college physics course [50,51]. The College Board indicated that 10582 students took AP Physics 1 in New York State in 2016-17 [52], an algebraic course in mechanics, basic electrostatics, simple dc circuits, and mechanical waves and sound. The College Board also indicated that 1629 students took AP Physics 2 in 2016-17 [52], an algebraic course in fluid mechanics, thermodynamics, electrostatics, electric circuits, magnetism and electromagnetism, optics, and modern physics. In some schools, AP Physics 1 was taught in conjunction with college-preparatory physics, and in some cases, it may also have been taught in conjunction with AP Physics 2 during a single academic year.

The final two courses were AP Physics $C$ Mechanics and $A P$ Physics $C$ Electricity and Magnetism, equivalent to college-level introductory calculus-based physics courses [53,54]. In New York State, AP C Mechanics and Electricity and Magnetism were often found combined into a single academic year course [52]. Additionally, AP C Mechanics was sometimes taught as a first-year course in lieu of AP Physics 1.

\section{Teacher-level variables}

Physics teacher isolation was a categorical variable distinguishing physics teachers of any physics course who were the only physics teacher in the school (isolated), as opposed to physics teachers who taught in schools with multiple physics teachers (nonisolated).

Professional age was the number of years since the first teaching certification was awarded; this continuous variable served as a proxy for physics teaching experience. 
Physics certification was identified by a series of categorical variables to distinguish among the following: (i) primary certification, typically awarded to teachers with a physics major or its equivalent; (ii) secondary certification, for those who had earned at least 18 physics credits, had passed the Physics Content Speciality Test, and had previously been certified in another subject (typically science or mathematics); and (iii) those with no physics certification (nonphysics certified).

\section{Data analysis}

The main database included all public school physics teachers in New York State for the 2016-17 academic year and was used to generate descriptive statistics on physics course offerings, physics course taking, physics teacher characteristics, and school-level characteristics.

To examine potential differences in student performance between schools with isolated teacher and nonisolated teachers, a subset of the main database that included only schools reporting scores for the state physics examination in 2016-17 was utilized. In order to protect students' confidentiality, the state suppressed the passing percentages of any schools that tested fewer than five students. A total of 62 schools had suppressed scores-29 rural, 12 suburban, and 21 urban. Of these schools, 47 had an isolated physics teacher, resulting in suppressed scores for 28 (10.2\% of) rural schools, 6 (1.7\% of) suburban schools, and 15 (5.5\% of) urban schools. Scores were suppressed for 171 students, which represented less than $1 \%$ of all students tested in physics - 83 from rural schools, 29 from suburban, and 59 from urban. Additionally, some schools offered physics courses in alternating years or simply did not offer the course at all; these schools were excluded from the analyses. Consequently, the present study examined a sample of 720 schools-260 with nonisolated physics teachers and 459 with isolated physics teachers.

Descriptive statistics were generated, and comparisons of means were assessed to compare student performance in physics for students of isolated teachers who taught college-prep physics and students of nonisolated physics teachers who taught the same course. These teachers were chosen since the outcome of student performance was the standardized exam for college-prep physics.

In order to study collective predictive value of the teacher-level and school-level variables, a subset of the main database including only isolated teachers who had associated physics student performance scores were used, as these teachers could be tied directly to their students' scores. This subset was also utilized to study the potential predictors of student performance in physics. Zero-order bivariate correlations were generated to identify predictor variables with significant relationships with student physics performance $(p<0.05)$. Multiple linear regression was employed to identify teacher and school-level variables that collectively predicted student performance in college-prep

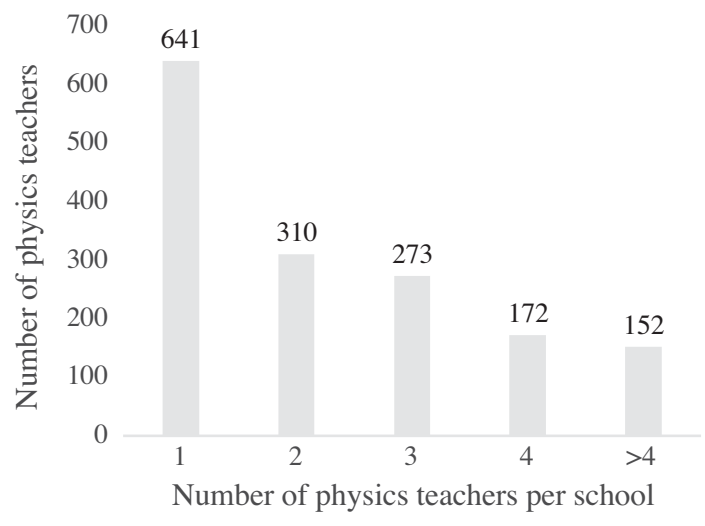

FIG. 2. Number of physics teachers in schools that taught physics.

physics coursework. Mediation analysis [55] was used to identify teacher characteristics that may have lessened the potential effect of socioeconomic variables on student performance.

\section{RESULTS}

\section{A. Characteristics of isolated and nonisolated physics teachers \\ 1. Prevalence of isolation}

In 2016-17, there were 1257 public high schools in the state, of which $960(76 \%)$ offered at least one course in physics. This result contrasts somewhat with a prior survey report that suggested much higher levels of physics availability nationally (90\%-97\%, depending on school-level socioeconomic status) [7]. Overall, there were 1584 teachers who taught at least one physics course. Of these teachers, $641(40 \%)$ were isolated while the majority of them $(60 \%)$ worked in schools with at least one other physics teaching colleague (see Fig. 2). The distribution of physics teachers across the schools is shown in Fig. 3. The most common numbers of physics teachers in schools were one and zero with 938 schools having one or no physics

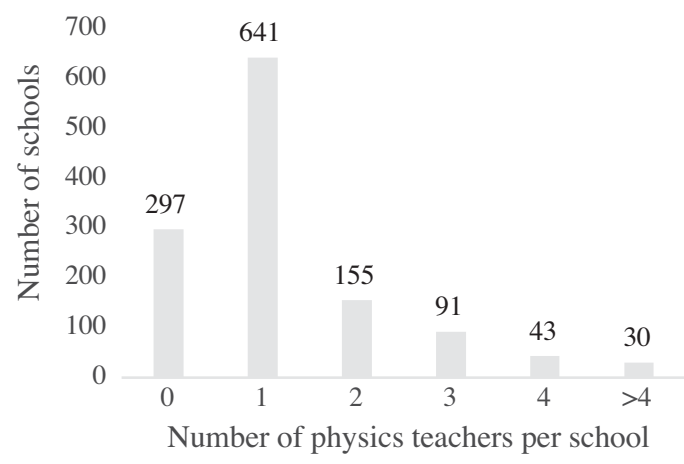

FIG. 3. Frequency of schools with isolated physics teachers in comparison to schools with nonisolated teachers. 


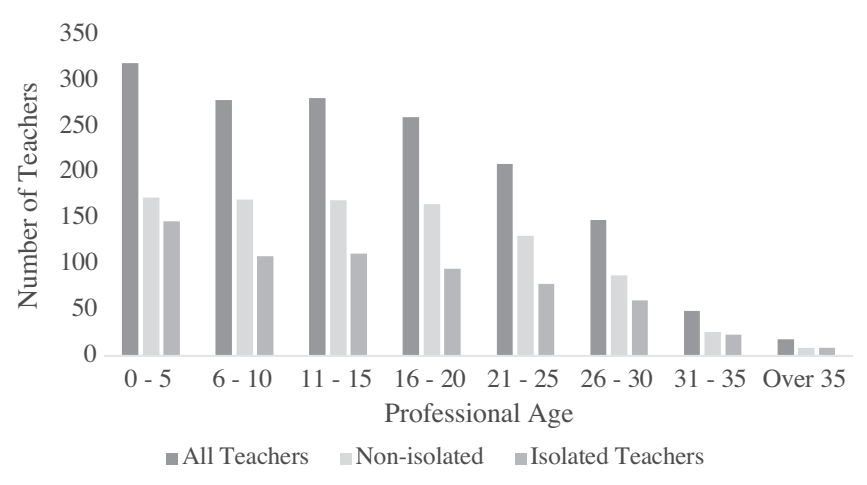

FIG. 4. Distribution of physics teachers by professional age.

teachers. Notably, $67 \%$ of the schools that offered physics had an isolated teacher.

\section{Teaching experience of isolated vs nonisolated teachers}

The average professional age of isolated physics teachers was $14.3 \mathrm{yr}(\mathrm{SD}=8.9 \mathrm{yr})$ and the average professional age for nonisolated teachers was $14.7 \mathrm{yr}(\mathrm{SD}=9.6 \mathrm{yr})$. An independent samples $t$ test indicated there was no significant difference in teaching experience between the two groups $(p=0.367)$. The distribution of physics teachers by professional age is represented in Fig. 4. The largest group of physics teachers had less than five years of teaching experience. This pattern was observed for isolated physics teachers, as well. The mean professional age of urban teachers was 11.0 years $(\mathrm{SD}=8.2 \mathrm{yr})$, suburban teachers had a mean professional age of $16.5 \mathrm{yr}$ $(\mathrm{SD}=9.0 \mathrm{yr})$, and rural teachers had a mean professional age of $16.1 \mathrm{yr}(\mathrm{SD}=9.4 \mathrm{yr})$.

Isolated teachers who did not teach students who took the standardized statewide college-prep physics exam were removed from the sample for data analysis on student performance. An independent samples $t$-test comparison of the mean student passing percentage on a high-stakes physics examination indicated that students in schools with nonisolated teachers $(N=260, M=79.64$, $\mathrm{SD}=17.11)$ outperformed students in schools with isolated teachers $(N=459, M=75.29, \mathrm{SD}=25.46)$ on the physics examination with a small effect size, $[t(696.572)=$ 2.732, $p<0.01$, Cohen's $d=0.20$ ].
Isolated college-prep physics teachers were selected for more in-depth analysis since their students did not perform as well as students of nonisolated teachers, and their student performance outcomes could be directly related to teacherlevel variables. Students of nonisolated teachers were reported as an aggregate school-level passing percentage, which masked individual differences among these teachers.

\section{Certifications of isolated vs nonisolated teachers}

The certifications of physics teachers throughout the state were identified in terms of primary, secondary, and noncertified categories. Overall, $77.0 \%$ of all physics teachers were certified in the subject, including 57.5\% with a primary license (degree or equivalent in physics) and $19.5 \%$ with a secondary license (at least 18 credits in physics). The remaining $23.0 \%$ of physics teachers did not hold a license in physics. For the isolated teachers, 69.3\% were certified in physics, $50.2 \%$ held a primary certification, and $19.0 \%$ held a secondary certification. A larger percentage $(29.7 \%)$ of the isolated teachers were uncertified than their counterparts. These descriptive data are summarized in Table II.

\section{School locale, physics teacher certification, and physics participation}

The physics teachers were categorized by the locale of their schools (urban, suburban, rural). Most schools $(37.1 \%)$ were suburban, yet these schools employed a high proportion of all physics teachers $(46.5 \%)$ and a disproportionately low proportion of isolated physics teachers (25.4\%). Rural schools employed the lowest percentage of all physics teachers $(19.1 \%)$ and the largest percentage of isolated physics teachers (39.9\%). Isolation among teachers was most prevalent in rural schools with $84.5 \%$ of rural physics teacher teaching in isolation, followed by $40.8 \%$ of urban teachers and $22.1 \%$ of suburban.

Physics participation was also analyzed by locale, and this was determined by the approximate percentage of eligible physics students (based on population of 12th grade students) who completed the college-preparatory physics course. Overall, $41.3 \%$ of high school students took college-preparatory physics, slightly higher than the

TABLE II. Certifications of isolated and nonisolated physics teachers.

\begin{tabular}{|c|c|c|c|}
\hline Teacher-level certification variables & $\begin{array}{c}\text { Nonisolated physics } \\
\text { teachers }(\%)\end{array}$ & $\begin{array}{l}\text { Isolated physics } \\
\text { teachers }(\%)\end{array}$ & $\begin{array}{c}\text { All physics } \\
\text { teachers }(\%)\end{array}$ \\
\hline Total number of teachers & 943 & 641 & 1584 \\
\hline Teacher is certified in physics & $776(82.3)$ & $444(69.3)$ & $1220(77.0)$ \\
\hline $\begin{array}{l}\text { Teacher holds a primary license } \\
\text { (degree in physics or equivalent) }\end{array}$ & 589 & 322 & 911 \\
\hline $\begin{array}{l}\text { Teacher holds a secondary license } \\
(18+\text { physics credits after licensed in other subject })\end{array}$ & 187 & 122 & 309 \\
\hline Teacher is uncertified in physics & $167(17.7)$ & $197(30.7)$ & $364(23.0)$ \\
\hline
\end{tabular}


TABLE III. Distribution of physics teachers, schools, students, and isolated teachers by locale.

\begin{tabular}{lcccccc}
\hline \hline Locale & $\begin{array}{c}\text { Physics teachers } \\
n(\% \text { of total) }\end{array}$ & $\begin{array}{c}\text { Isolated physics } \\
\text { teachers } n(\%)\end{array}$ & $\begin{array}{c}\text { Schools } \\
n(\%)\end{array}$ & $\begin{array}{c}\text { Physics students } \\
n(\%)\end{array}$ & $\begin{array}{c}12^{\text {th }} \text { grade } \\
\text { students }\end{array}$ & $\begin{array}{c}\text { Percentage of } 12^{\text {th }} \text { grade } \\
\text { students taking physics }\end{array}$ \\
\hline Urban & $544(34.3)$ & $222(34.6)$ & $329(34.3)$ & $32229(41.0)$ & 79831 & 40.4 \\
Suburban & $737(46.5)$ & $163(25.4)$ & $356(37.1)$ & $37993(48.3)$ & 85553 & 44.4 \\
Rural & $303(19.1)$ & $256(39.9)$ & $275(28.6)$ & $8454(10.7)$ & 25261 & 33.5 \\
Total & 1584 & 641 & 960 & 78676 & 190645 & 41.3 \\
\hline \hline
\end{tabular}

national average of high school physics participation [6]. Suburban schools had the highest rate of physics participation $(44.4 \%)$, followed by urban $(40.4 \%)$ and rural $(33.5 \%)$ schools.

These descriptive data are summarized in Table III.

Teacher certification was also examined by locale. In urban schools, only $57.6 \%$ of all physics teachers and $53.6 \%$ of the isolated urban teachers were physics certified. In the rural locale, $76.3 \%$ of all physics teachers and $73.4 \%$ of the isolated teachers were certified in physics. In the suburban schools, $91.5 \%$ of all teachers and $83.4 \%$ of the isolated teachers were certified in physics.

In summary, there were several notable differences between isolated and nonisolated physics teachers. A significant proportion $(40.5 \%)$ of physics teachers were isolated, and their students tended to have lower physics performance scores than students of nonisolated teachers. Compared to the non-isolated teachers, a larger percentage of isolated physics teachers were uncertified in physics. Isolated physics teachers were more common in urban and rural schools than suburban schools. There was no significant difference in professional age between isolated and nonisolated teachers.

\section{B. Descriptive statistics on physics teaching and course taking \\ 1. Physics course taking}

During the 2016-17 school year, there were 78676 students who were enrolled in physics courses in the state. Using the ratio of students enrolled in physics compared to the total number of 12 th grade students, a maximum $41.3 \%$ of students took a physics course prior to graduation, consistent with recent national trends [6]. Suburban schools had the largest percentage of possible 12th grade students taking physics (44.4\%), followed by urban schools (40.4\%) and rural schools (33.5\%). There were 2217 sections of college-prep physics offered to 46957 students with 47905 students tested [45]. The discrepancy between the number of students taking the course and taking the test occurred due to students retaking the exam or students taking the exam not enrolled in the course. The second most commonly occurring course was known as other physics, followed by AP Physics B, AP Physics C Mechanics, and AP Physics C Electricity and Magnetism. The prevalence of physics course type in all state high schools is represented in Table IV.

Course taking was also examined in terms of schools with isolated physics teachers. These schools generally offered less physics course sections, with many of the courses falling into the college-prep and other physics categories. Very few of these schools offered AP Physics B, AP Physics C Mechanics, and AP Physics Electricity \& Magnetism. Regardless of the course type, the majority of schools with isolated physics teachers offered two or fewer sections of physics courses, as shown in Table V.

In terms of locale, urban schools had 10869 students taught by isolated physics teachers, or $36.1 \%$ of their physics student population. Rural schools had lower raw numbers of students taught by isolated teachers (5346), but the highest percentage of students taking physics taught by an isolated teacher (63.2\%). Suburban schools had a similar number of students taught by isolated teachers as rural schools (6347), with $17.2 \%$ of their students taught by an

TABLE IV. Prevalence of physics courses in schools that offered physics.

\begin{tabular}{|c|c|c|c|c|c|}
\hline \multirow[b]{2}{*}{$\begin{array}{l}\text { Number of } \\
\text { sections offered }\end{array}$} & \multicolumn{5}{|c|}{ Number of schools offering each course $(\%)$} \\
\hline & $\begin{array}{l}\text { College-prep } \\
\text { or regents }\end{array}$ & AP Physics B & $\begin{array}{l}\text { AP Physics } \\
\text { C Mechanics }\end{array}$ & $\begin{array}{l}\text { AP Physics } \\
\text { C E\&M }\end{array}$ & $\begin{array}{l}\text { Other } \\
\text { physics }\end{array}$ \\
\hline 0 & $130(13.5)$ & $728(75.8)$ & $843(87.8)$ & 915 (95.3) & $559(58.2)$ \\
\hline 1 & $352(36.7)$ & $136(14.2)$ & 107 (11.1) & $44(4.6)$ & 179 (18.6) \\
\hline 2 & $186(19.4)$ & $46(4.8)$ & $9(0.9)$ & $1(0.1)$ & $97(10.1)$ \\
\hline 3 & $90(9.4)$ & $25(2.6)$ & $1(0.1)$ & $\ldots$ & $48(5)$ \\
\hline 4 & $75(7.8)$ & $14(1.5)$ & $\ldots$ & $\cdots$ & $27(2.8)$ \\
\hline $5 \geq$ & 127 (13.2) & $11(1.1)$ & $\ldots$ & $\ldots$ & $50(5.2)$ \\
\hline Total schools & $960(100)$ & $960(100)$ & $960(100)$ & $960(100)$ & $960(100)$ \\
\hline
\end{tabular}


TABLE V. Prevalence of physics courses in schools of isolated physics teachers.

\begin{tabular}{|c|c|c|c|c|c|}
\hline \multirow[b]{2}{*}{$\begin{array}{l}\text { Number of } \\
\text { sections offered }\end{array}$} & \multicolumn{5}{|c|}{ Number of isolated schools offering each course $(\%)$} \\
\hline & $\begin{array}{l}\text { College-prep } \\
\text { or regents }\end{array}$ & AP Physics B & $\begin{array}{l}\text { AP Physics } \\
\text { C Mechanics }\end{array}$ & $\begin{array}{l}\text { AP Physics } \\
\text { C E\&M }\end{array}$ & $\begin{array}{l}\text { Other } \\
\text { physics }\end{array}$ \\
\hline 0 & $96(15)$ & $566(88.3)$ & $620(96.7)$ & $638(99.5)$ & 448 (69.9) \\
\hline 1 & $324(50.5)$ & $66(10.3)$ & $21(3.3)$ & $3(0.5)$ & $114(17.8)$ \\
\hline 2 & $144(22.5)$ & $8(1.2)$ & $\ldots$ & $\ldots$ & $46(7.2)$ \\
\hline 3 & $45(7)$ & $1(0.2)$ & $\ldots$ & $\ldots$ & $22(3.4)$ \\
\hline 4 & $23(3.6)$ & $\ldots$ & $\ldots$ & $\ldots$ & $8(1.2)$ \\
\hline $5 \geq$ & $9(1.4)$ & $\ldots$ & $\ldots$ & $\ldots$ & $3(0.5)$ \\
\hline Total schools & $641(100)$ & $641(100)$ & $641(100)$ & $641(100)$ & $641(100)$ \\
\hline
\end{tabular}

isolated teacher. Overall 23394 (29.7\%) of physics students were taught by an isolated teacher, yet this percentage varied notably by locale.

\section{Physics course load}

The fraction of course load taught in physics was an additional consideration when analyzing teacher-level variables. Slightly more than half $(54.6 \%)$ of all physics teachers taught courses in other disciplines, either in another science or mathematics. Fewer than half $(38.0 \%)$ of physics teachers taught less than $50 \%$ of their course load in physics. Those who taught other science courses were most likely to teach science electives or chemistry. Table VI indicates the number of designated physics teachers according to the percentage of their course load in various sciences and mathematics.

Analysis of variance (ANOVA) with a Tukey post hoc test indicated that there was a significant difference in the mean course load among isolated physics teachers depending upon school locale. There was a significant difference between the mean percentage physics course load of isolated teachers in rural schools $(M=0.502$, $\mathrm{SD}=0.286, p<0.001)$ and both urban schools $(M=$ $0.648, \mathrm{SD}=0.310)$ and suburban schools $(M=0.709$, $\mathrm{SD}=0.293, p<0.001)$. However, there was no significant difference between the course loads of physics teachers in suburban schools and urban schools $(p=0.247)$. The model was significant with a medium to large effect size $(F(2446)=22.325, p<0.001$, Cohen's $d=0.63)$. Descriptive statistics for the course load of isolated physics teachers are presented in Table VII.

In summary, urban schools had the largest number of students taught by isolated physics teachers, though rural schools had the largest percentage of their students taught by an isolated physics teacher. Suburban schools enrolled the largest number of physics students among the three locales, and had the smallest number taught by an isolated teacher. The majority of schools with only one physics

TABLE VI. Course load of all physics teachers $(N=1584)$.

\begin{tabular}{|c|c|c|c|c|c|c|}
\hline \multirow[b]{2}{*}{ Teaching load \% } & \multicolumn{6}{|c|}{ Number of physics teachers teaching in discipline $(\%)$} \\
\hline & Physics & Chemistry & Biology & Earth science & Other science(s) & Mathematics \\
\hline 0 & & $1329(83.9)$ & $1448(91.4)$ & 1409 (89) & $1194(75.4)$ & $1476(93.2)$ \\
\hline $1-25$ & $245(15.5)$ & $54(3.4)$ & $45(2.8)$ & $48(3)$ & $146(9.2)$ & $17(1.1)$ \\
\hline $26-50$ & $356(22.5)$ & $114(7.2)$ & $48(3)$ & $76(4.8)$ & $176(11.1)$ & $39(2.5)$ \\
\hline $51-75$ & $243(15.3)$ & $80(5.1)$ & $33(2.1)$ & $41(2.6)$ & $54(3.4)$ & $35(2.2)$ \\
\hline$>75$ & $740(46.7)$ & $7(0.4)$ & $10(0.6)$ & $10(0.6)$ & $14(0.9)$ & $17(1.1)$ \\
\hline
\end{tabular}

TABLE VII. Course load of the isolated physics teachers $(N=641)$.

\begin{tabular}{|c|c|c|c|c|c|c|}
\hline \multirow[b]{2}{*}{ Teaching load \% } & \multicolumn{6}{|c|}{ Number of physics teachers teaching in discipline $(\%)$} \\
\hline & Physics & Chemistry & Biology & Earth science & Other science(s) & Mathematics \\
\hline 0 & $\ldots$ & $491(76.6)$ & $578(90.2)$ & $533(83.2)$ & $452(70.5)$ & $573(89.4)$ \\
\hline $1-25$ & $156(24.3)$ & $22(3.4)$ & $21(3.3)$ & $25(3.9)$ & $69(10.8)$ & $13(2)$ \\
\hline $26-50$ & $189(29.5)$ & $78(12.2)$ & $24(3.7)$ & $51(8)$ & $79(12.3)$ & $21(3.3)$ \\
\hline $51-75$ & $95(14.8)$ & $48(7.5)$ & $14(2.2)$ & $23(3.6)$ & $34(5.3)$ & $20(3.1)$ \\
\hline$>75$ & $201(31.4)$ & $2(0.3)$ & $4(0.6)$ & $9(1.4)$ & $7(1.1)$ & $14(2.2)$ \\
\hline
\end{tabular}


TABLE VIII. Potential predictors of physics performance.

\begin{tabular}{|c|c|c|c|}
\hline Independent variables & Correlation coefficient & $N$ & $p$ value \\
\hline \multicolumn{4}{|c|}{ Teacher-level variables related to certification/preparation } \\
\hline Professional age (years of teaching experience, continuous) & $r=0.261^{* * *}$ & 449 & $<0.001$ \\
\hline Primary physics certification (yes/no, binary) & $r_{s}=0.107^{*}$ & 449 & 0.023 \\
\hline Secondary physics certification (yes/no, binary) & $r_{s}=0.147^{* *}$ & 449 & 0.002 \\
\hline Physics certification (yes/no, binary) & $r_{s}=0.032$ & 449 & 0.502 \\
\hline \multicolumn{4}{|c|}{ Teacher-level variables related to course load } \\
\hline Taught AP course (yes/no, binary) & $r_{s}=0.074$ & 449 & 0.119 \\
\hline Number of different physics courses taught (continuous) & $r_{s}=0.050$ & 449 & 0.292 \\
\hline Taught mathematics (yes/no, binary) & $r_{s}=0.008$ & 449 & 0.870 \\
\hline Fraction of course load taught in physics (continuous) & $r=0.029$ & 449 & 0.543 \\
\hline \multicolumn{4}{|c|}{ School-level variables } \\
\hline Rural locale (yes/no, binary) & $r_{s}=0.371^{* * *}$ & 449 & $<0.001$ \\
\hline Suburban locale (yes/no, binary) & $r_{s}=0.038$ & 449 & 0.420 \\
\hline Urban locale (yes/no, binary) & $r_{s}=-0.478^{* * *}$ & 449 & $<0.001$ \\
\hline Percentage of students qualified for free/reduced lunch & $r=-0.504^{* * *}$ & 449 & $<0.001$ \\
\hline School population in grades $9-12$ (continuous) & $r=0.058$ & 447 & 0.223 \\
\hline Physics test-taking ratio (continuous) & $r=0.119^{*}$ & 447 & 0.012 \\
\hline
\end{tabular}

teacher offered two or less sections of college-prep physics, and very few advanced or second year physics courses. The majority of isolated teachers taught physics for $50 \%$ or less of their teaching load. Isolated physics teachers in rural schools taught significantly less physics in their course loads than both urban and suburban teachers.

\section{Predictors of performance in physics: Students of isolated physics teachers}

\section{Correlating factors}

Since various contextual factors differed for isolated physics teachers, inferential statistics were generated to identify significant predictors of the physics performance of their students. Of the 459 isolated teachers with reported physics scores for their students, 10 were removed due to missing certification and professional age, resulting in 449 isolated physics teachers for subsequent analysis. To perform a multiple linear regression, it was necessary to determine individual predictors that correlated to physics performance. A normal P-P plot of regression standardized residual indicated assumptions of normality and homogeneity were met for the following continuous variables: percentage passing rate on the physics standardized exam $(M=75.86 \%, \quad \mathrm{SD}=24.9 \%)$, test-taking ratio ( $M=0.0513, \mathrm{SD}=0.0735)$, fraction of course load taught in physics $(M=0.601, \mathrm{SD}=0.308)$, school size $(M=917$, $\mathrm{SD}=808)$, and professional age $(M=15.16, \mathrm{SD}=9.29)$. Variance inflation factors (VIFs) were all $<2$, indicating there was no multicollinearity among predictor variables. Missing data were deleted listwise.

To test assumptions of linearity, bivariate Pearson or Spearman correlations indicated the following variables were significantly correlated with the percentage passing rate on the standardized exam: (i) professional age, (ii) primary certification status, (iii) secondary certification status; (iv) school classification of urban, (v) rural locale, (vi) percentage of students qualifying for free and reduced lunch, and (vii) physics test-taking ratio. The following variables were not significantly correlated with student performance in physics, and were thus eliminated from the multivariable model: (i) whether the teacher was certified in physics, (ii) whether teachers taught an AP physics course, (iii) number of different physics courses taught; (iv) whether teachers taught mathematics; (v) fraction of course load taught in physics; (vi) school classification of suburban; and (vii) school population in grades 9-12. Bivariate correlation statistics are summarized in Table VIII.

\section{Multiple linear regression model}

Multiple linear regression was performed to predict physics passing rate based on the independent variables of (i) primary physics certification status, (ii) secondary certification status; (iii) school classification of urban; (iv) school classification as rural; (v) percentage of students qualifying for free and reduced lunch; (vi) physics testtaking ratio, and (vii) professional age. 
TABLE IX. Multivariable regression model.

\begin{tabular}{|c|c|c|c|c|c|}
\hline \multirow[b]{2}{*}{ Variable } & \multirow{2}{*}{$\begin{array}{c}\text { Standardized regression } \\
\text { coefficient } \beta\end{array}$} & \multirow{2}{*}{$\begin{array}{l}\text { Unstandardized } \\
\text { regression coefficient } B\end{array}$} & \multicolumn{2}{|c|}{$95 \%$ Confidence interval } & \multirow[b]{2}{*}{$p$ value } \\
\hline & & & Lower & Upper & \\
\hline Urban school locale & -0.301 & -17.705 & -24.280 & -11.129 & $<0.001$ \\
\hline Socioeconomic status (\%FRL) & -0.229 & -0.298 & -0.434 & -0.163 & $<0.001$ \\
\hline Rural school locale & 0.151 & 7.565 & 3.268 & 11.863 & 0.001 \\
\hline Professional age & 0.109 & 0.278 & 0.063 & 0.492 & 0.011 \\
\hline
\end{tabular}

Four variables were significant predictors of student performance in physics-school classification of urban locale, school classification of rural, percentage of students qualifying for free and reduced lunch, and professional age. A significant regression was found $[F(7,439)=39.685$, $p<0.001]$; the adjusted $R^{2}$ was 0.378 , a large effect. The regression equation was the following:

School-level physics passing percentage

$=88.286-17.705$ (urban schoollocale)

-0.298 (percentage qualifying for free/reduced lunch)

+7.565 (rural school locale $)+0.278$ (professional age)

where urban school locale was coded $1=$ urban schools, and $0=$ suburban or rural schools, and rural school locale was coded $1=$ rural schools and $0=$ suburban or urban schools. The following three variables were not significant in the multivariable model: physics test-taking ratio, suburban locale, and secondary physics certification. The multivariable regression model statistics are shown in Table IX.

\section{Mediation analysis}

The main predictors of student physics performance included the independent variables of school location (urban and rural) and socioeconomic status. These independent variables were defined as fixed since they were not subject to change in terms of the types of schools students attended, however, professional age, or years of teaching experience, is a teacher-level variable that may be influenced by working conditions in specific schools [22-24]. Consequently, a mediation analysis was performed to see whether professional age lessened the impact of school poverty and location on student physics performance. Baron and Kenny [55] designed a process to determine whether a third variable (the mediator, or professional age) diminished the predictive value of the independent variable (the predictor, urban school locale, or socioeconomic status), which may establish a causal mechanism for the dependent variable (student performance).

Two mediation analyses were performed. In the first analysis, urban school locale was the predictor, student physics performance was the dependent variable, and professional age was the potential mediator. Results indicated that, for the subpopulation of isolated physics teachers $(N=449)$, urban school locale was a significant predictor of physics passing rate $(\beta=-0.561, p<0.001)$. Urban school locale also predicted professional age, or teaching experience $(\beta=-0.256, p<0.001)$. A multiple regression model revealed that urban school locale and professional age predicted physics passing rate (urban school locale $\beta=-0.529, p<0.001$; professional age $\beta=0.125, p=0.002$ ), supporting the mediational hypothesis. Since urban school locale was a weaker yet significant

TABLE X. Professional age as a mediator of physics performance.

\begin{tabular}{|c|c|c|c|c|c|c|c|c|c|c|}
\hline \multicolumn{11}{|c|}{ First model ${ }^{*}$} \\
\hline $\begin{array}{l}\text { Testing } \\
\text { path }\end{array}$ & $\begin{array}{l}\text { Independent } \\
\text { variable }\end{array}$ & Dependent variable & Effect & Adjusted $R^{2}$ & df & $F$ & $\beta$ & $B$ & $S E(B)$ & $95 \% \mathrm{CI}$ \\
\hline$c$ & Urban locale & Physics passing rate & Direct & 0.313 & 448 & 205.419 & -0.561 & -32.964 & 2.300 & $-37.484,-28.444$ \\
\hline$a$ & Urban locale & Professional age & Mediated & 0.064 & 448 & 31.452 & -0.256 & -5.623 & 1.003 & $-7.594,-3.653$ \\
\hline$b$ & Professional age & Physics passing rate & Mediated & 0.327 & 448 & 109.615 & 0.125 & 0.336 & 0.107 & $0.125,0.547$ \\
\hline$c^{\prime}$ & Urban locale & Physics passing rate & Indirect & $\begin{array}{c}\cdots \\
\text { Second mode }\end{array}$ & & $\ldots$ & -0.529 & -31.075 & 2.356 & $-35.706,-26.444$ \\
\hline$c$ & SES & Physics passing rate & Direct & 0.252 & 448 & 152.225 & -0.504 & -0.656 & 0.053 & $-0.760,-0.551$ \\
\hline$a$ & SES & Professional age & Mediated & 0.046 & 448 & 22.386 & -0.218 & -0.106 & 0.022 & $-0.150,-0.062$ \\
\hline$b$ & Professional age & Physics passing rate & Mediated & 0.275 & 448 & 85.853 & 0.159 & 0.425 & 0.110 & $0.208,0.642$ \\
\hline$c^{\prime}$ & SES & Physics passing rate & Indirect & $\ldots$ & $\ldots$ & $\ldots$ & -0.469 & -0.611 & 0.054 & $-0.716,-0.505$ \\
\hline
\end{tabular}

*Multivariable models, $p<0.001$. 
predictor of physics passing rate in the multiple regression model, the relationship between urban school locale and physics passing rate was partially mediated by professional age. The standardized indirect effect $[(a)(b)]$ was $(0.256)(0.125)=0.032$, a small to medium effect.

In the second analysis, socioeconomic status was the predictor, student physics performance was the dependent variable, and professional age was the potential mediator. Socioeconomic status was a significant predictor of physics passing rate $(\beta=-0.504, p<0.001)$. Socioeconomic status also predicted professional age $(\beta=-0.218$, $p<0.001)$. The multiple regression model revealed that socioeconomic status and professional age predicted physics passing rate (SES $\beta=-0.469, p<0.001$; professional age $\beta=0.159, p<0.001$ ), supporting the hypothesis that physics performance in high poverty schools was partially mediated by professional age. The standardized indirect effect was 0.035 , a small to medium effect. Mediation results are summarized in Table $\mathrm{X}$.

\section{DISCUSSION}

\section{A. Conclusions}

This research was framed by theoretical constructs related to workplace tensions for isolated teachers, as well as equity considerations in precollege physics education. Statistical analyses identified the prevalence of physics teacher isolation and disparities among school contexts and physics access and performance. The main conclusions of the study are discussed in terms of physics teacher isolation and physics access, physics education challenges related to high poverty schools, and the success of physics education in rural contexts.

\section{Teacher isolation and physics access and course taking}

Results indicated that less than half of state physics teachers $(40.5 \%)$ taught in isolation during the 2016-17 school year, which is much lower than national estimates of $80 \%$ [20]. Students from schools with isolated physics teachers demonstrated weaker physics performance compared to students from schools with multiple physics teachers, with a small to medium effect size. These findings are consistent with a similar study concerning isolated chemistry teachers [15]. Isolation was found to have a significant relationship with previously reported issues regarding physics access and equity for students, which may have been exacerbated by previously reported teacher workplace tensions associated with isolated working environments, including limited pedagogical development, occupational stress, and lack of social integration among peer educators $[22,23,30,56]$.

Isolated teachers tended to work in schools that offered two or fewer sections of college-prep physics and other physics, with very few offerings of Advanced Placement physics courses. This had a direct relationship with both student access to physics courses as well as isolated teacher course load. In line with previous research, the majority of isolated teachers were not full-time physics teachers, rather, they also taught STEM courses such as chemistry, earth science, and mathematics [6,7,15,34]. Students who attended schools with an isolated teacher often experienced restricted access to advanced and second year physics courses, both previously reported to strengthen a student's likelihood of STEM interest and persistence $[2,4,5]$.

School locale and socioeconomic status and teaching experience were the predictors in the multivariable model, with experience acting as a partial mediator for poverty. This suggests that overcoming constraints such as poverty and limited resource allocation should be a major consideration in physics teacher preparation. Notably, several isolated teacher-level variables were not significant predictors of physics performance. These included physics certification (primary, secondary, or none), course load taught in physics, and whether other subjects were taught by the teacher. This suggests that the physics content preparation of the teacher did not seem to affect student performance at the college-prep physics level.

\section{Challenges related to physics education in urban, high poverty schools}

While previous research has identified equity concerns with regard to physics education and high need school teaching for both students and teachers [7-12,19,23], these disparities were more prominent with isolated physics teachers in urban schools. Both urban locale and low socioeconomic status were negative predictors of physics performance, an outcome consistent with previous research regarding the inequities and challenges of teaching in these environments $[14,15]$. Distribution of isolated teachers among the three school locales was inequitable. Nearly half of all urban physics teachers were working in isolation and a majority of urban schools (67.5\%) employed only a single physics teacher.

Conversely, a much lower percentage of suburban teachers $(22.2 \%)$ were isolated. The hiring of multiple physics teachers increases the capability of a school to offer more sections of physics, as well as more advanced and second year courses. Additionally, this also expands opportunities for suburban teachers to work with other physics teachers within their departments, a scenario severely limited in both rural and urban schools.

There were disparities in professional age among the three locales, with urban schools employing the least experienced teachers out of the three locales. Rural and suburban schools had similar professional ages, on average five years more experienced than urban teachers. Urban schools have been shown to have higher turnover due to workplace tensions, which may be the reason for employing physics teachers with less experience. This is notable 
since professional age was also found to be a positive predictor, as well as a partial mediator of urban locale and low socioeconomic status, supporting the importance of teacher retention and experience highlighted in previous studies $[15,21,27]$.

\section{Successes and limitations of physics education in rural schools}

Rural locales were a positive predictor of physics performance in the multivariable model, suggesting there may be underlying pedagogical and school characteristics that should be explored in these contexts. Although rural science education has been neither easily defined nor extensively studied [57], there may be common attributes in rural academic contexts to inform physics educational reforms.

With many rural physics teachers working in isolation $(84.5 \%)$, there may have been a limited amount of physics sections offered, which was reflected in the relatively low percentage $(33.5 \%)$ of students taking physics in rural high schools. This suggests there may be a limited number of physics course taking opportunities due to the prevalence of isolated teachers in rural schools. There may also be a selection effect, where physics access is restricted to students with higher perceived competence or those who have taken higher level mathematics and science as prerequisites, consistent with prior research on physics in urban schools [23,35,58,59]. Additional research is needed to explore the promotion of physics course taking among rural students; this may inform efforts to improve physics access in urban schools, as well.

Rural students tended to outperform students in urban schools, despite the frequency of physics teacher isolation in both settings. The nature of rural schooling suggests that science curricula need to be comprehensive and clearly articulated across grade levels [60], which may contribute to a more prominent institutional emphasis on developing students' physics knowledge. With such a significant number of teachers working in isolation, there may be systemic regional supports in place (e.g., mentorship, teacher leadership, professional development) to optimize teacher success without the benefit of physics colleagues in the same building. Physics teacher preservice programs that serve rural schools may offer insights into effective teacher preparation for content specialists in isolated environments, many of whom must prepare multiple types of science classes every day [61]. This is an important consideration since nearly all rural schools in the state $(93.1 \%)$ employed a teacher who was certified in physics. Research has shown rural science teacher education programs have demonstrated the effectiveness of distance-based instructional coaching, particularly synchronous, interactive online professional learning with higher education institutions $[62,63]$. Such interventions may prevent or alleviate tensions associated with teacher isolation.

\section{B. Implications}

\section{Physics teacher preparation and induction}

The results of this study suggest several important implications for physics teachers, physics teacher preparation programs, science administrators, and school district administrators. In terms of teacher-level characteristics, student physics performance was predicted by teacher experience, yet certification type was not significant in the multivariable model. This suggests that physics teacher preparation programs may have room for improvement. If the amount of coursework in these programs, which typically includes both pedagogical and content-based experiences, is not predictive of student performance, then future reforms should focus on how these courses might be redesigned to optimize teaching and learning. Experience is valuable but it should not be the sole mediating factor when considering school contexts as predictors of performance.

The proportion of isolated physics teachers may be less than previously recorded [11], however isolation may exacerbate contextual inequities for both teacher professional support and student access. In terms of preservice teachers, it is recommended that physics teacher education programs encourage the development of programs that prepare teachers for the contextual constraints of schools in different locales. Also, the needs of specific locales may dictate how physics teacher production can be targeted to optimize efficiency and equity.

Compounding this problem, a noticeable portion of physics teachers in this study taught out-of-subject. Consequently, it is also important that science teachers have a breadth of science courses in their background, as it is likely they will teach other disciplines, particularly in rural locales. This also raises concerns for isolated novice teachers as they had to navigate their first years of teaching while also contending with out-of-subject teaching. Isolated physics teachers, specifically novice teachers, should be given access to materials and curriculum for all their assigned course load so they may focus on developing pedagogical content knowledge as opposed to developing curriculum. Furthermore, it is recommended that isolated teachers be observed by those who are trained to evaluate their subject specific pedagogical abilities and provide feedback to improve their practice.

These findings suggest that isolated teachers may require more context specific professional support during the critical induction years. A direct implication of isolation is the reduced ability for schools to provide the recommended mentoring during the vital induction period [21]. This is a particular concern for isolated novice teachers, as isolated teachers tend to have fewer collegial interactions [23]; such connectedness with colleagues has been shown to decrease attrition [56]. Research has shown that novice teachers in physics demonstrated an increase in effectiveness with more years of experience [21], demonstrating the 
importance of mentoring and professional networks to combat attrition $[23,24]$.

Several studies have proposed the development of social networks and professional learning communities to strengthen reflective habits in new teachers [56,64-67], something that may not be difficult for isolated physics teachers. Professional communities such as local AAPT chapters may provide professional growth opportunities for enriching teaching practice while also easing workplace tensions associated with isolated teaching. Furthermore, these may facilitate collegial interactions so teachers receive feedback from educators trained in physics - something their schools cannot provide.

\section{Equity in physics access and course taking}

School locale and socioeconomic status were the main predictors of physics performance in the multivariable model. Prior research has shown that as socioeconomic status decreases, access to physics decreases as many high poverty schools do not offer physics or only offer physics every other year $[9,12,14]$. The weak physics performance of students in these schools may be related to poor mathematical preparation, state testing mandates, and a deficit view of traditionally underrepresented students in physics [23,35]. By prioritizing physics course taking, instituting a strong science culture, and improving preparation for success in physics, a school may facilitate more equitable student outcomes. In turn, this may promote the participation of traditionally underrepresented minorities in STEM fields and underserved students in general.

Too often, physics has been viewed as a course for academically elite students, which might restrict access to a gateway course necessary for post-secondary STEM success. By requiring physics for graduation, all students might have equal opportunity to achieve physics competency and literacy. Physics teachers, as well as administrators, should support all students taking physics, not just the more advanced students. This is particularly important in urban contexts, where students have traditionally experienced restricted access to advanced STEM coursework. By expanding physics access and interest, more physics teachers may be hired and the level of teacher isolation would diminish.

\section{Limitations}

There were several limitations in this study. First, this was a case study of a single state within the U.S. Most $\mathrm{K}-12$ educational policy is established at the state level, and the results from this study may not be generalizable to other states with widely divergent contextual characteristics. However, the state-level availability of verified teacher data and student physics examination performance may be instructive for other states to initiate reforms in secondary physics education policy to improve accessibility and performance, based on the use of such evidence.
Second, the standardized physics scores may not be an accurate assessment of students' physics knowledge. Scores were reported as aggregate averages of schools themselves, which may mask variations in teacher quality when examining schools with multiple physics educators. Because of the nature of the state-verified data analyzed in this quantitative study, information regarding the teaching methods of specific teachers was not part of the analysis. Furthermore, only students of isolated teachers were included in the multivariable analysis since those scores could be directly tied to individual teachers. This limited the analysis by excluding the students who attended schools with multiple physics educators.

Third, the classification of physics courses by the state had some ambiguities. Some Advanced Placement courses were designated as "Physics B," although that course was being phased out at the time of the study. "Other physics" was an inclusive set of courses with no set curricula, and this group included courses such as "honors physics" and International Baccalaureate physics courses. Some schools may have placed Advanced Placement courses in the other physics category, since the prevalence of these sections seemed to be underreported. Some schools only offered physics every other year and these schools were not in the sample. Scores of some schools were suppressed since fewer than five students were tested in physics; this disproportionately affected rural schools, with $10.2 \%$ of their schools removed from the isolated physics teacher sample.

Fourth, only one academic year of data was utilized for this study, requiring isolation to be narrowly defined. There may be factors related to a teacher's isolation within the school that were not reflected in the data, for example, having a supervisor that was a former physics teacher, working with a colleague pursuing a certification in physics, being a member of outside physics social networks, and/or previously working as a nonisolated physics teacher.

Finally, the teaching experience for these teachers was based on their professional age, or years since first certification, as the exact amount of working years for each teacher was not available. Teachers may have experienced breaks in service that were not reflected in the data.

\section{Future research}

This work has raised several questions that may be addressed in future research. As educational policy is determined largely at the state level, the methodologies employed in the present study would lend itself to replication in other states and in other subjects. With the wealth of data that states gather as required by No Child Left Behind and other legislation, these studies might provide deeper understandings of contextual factors that influence policies regarding physics teacher training, access to physics, and student performance in physics. 
These policies, largely determined at the state level, could be adjusted based upon the needs of students in specific state populations. Such a segmented approach may increase physics equity in terms of teacher preparedness, course access, and student performance.

The methodology utilized in this study would also lend itself to longitudinal studies. Questions regarding physics access, teacher certification, and teacher turnover could be answered by looking at data over the course of five-year or ten-year periods, providing information that may be used for identifying trends and highlighting effective physics education policy. These data may inform policy and practice, but to date they have largely been underutilized.

Interventions and conditions may be explored to examine how to improve physics teacher preparation across contexts and experience levels. Preservice programs and inservice professional development may be revised to better support teachers in their specific working environments. Rural schools, where many teachers work in isolation, may provide lessons in teacher resilience, teacher network development, and cross-disciplinary pedagogical development. Social network analysis could offer a methodological approach for understanding the collegial interactions among teachers, professional organizations and the support structures they utilize [56]. This would provide a foundation for understanding how these interactions differ between isolated and non-isolated teachers. Social networks have often been suggested as a plausible way to establish intellectual communities for physics teachers $[56,64,65]$, however, more empirical studies are needed to operationalize key elements of such interventions.

With professional age as a predictor of student performance, and a mediator of both local and socioeconomic status, the retention of isolated and nonisolated novice teachers should be explored. An understanding of factors that support physics teacher retention may increase the commitment of novice teachers to work in specific working environments, particularly high need schools in urban districts. Such interventions could include more robust induction support in the form of mentoring, formalized inter-school physics teacher networks with face-to-face interaction, and university-based professional learning communities.

\section{ACKNOWLEDGMENTS}

The authors would like to thank Linda Padwa and the anonymous reviewers for their insightful recommendations for this manuscript. This material is based upon work supported by the National Science Foundation under Grant No. 1035314.
[1] ACT, Developing the STEM Education Pipeline (ACT, Washington, DC, 2006).

[2] W. Tyson, R. Lee, K. M. Borman, and M. A. Hanson, Science, technology, engineering, and mathematics (STEM) pathways: High school science and math coursework and postsecondary degree attainment, J. Educ. Students Placed at Risk 12, 243 (2007).

[3] W. Tyson, Modeling engineering degree attainment using high school and college physics and calculus coursetaking and achievement, J. Eng. Educ. 100, 760 (2011).

[4] X. Wang, Why students choose STEM majors: Motivation, high school learning, and postsecondary context of support, Am. Educ. Res. J. 50, 1081 (2013).

[5] P. M. Sadler, G. Sonnert, Z. Hazari, and R. Tai, The role of advanced high school coursework in increasing stem career interest, Sci. Educat. 23, 1 (2014), https://eric.ed.gov/? id=EJ1034751.

[6] S. White and C. L. Tesfaye, High school Physics Courses and Enrollments: Results from the 2012-13 Nationwide Survey of High School Physics Teachers (American Institute of Physics, College Park, MD, 2014), https:// www.aip.org/statistics/reports/high-school-physicscourses-enrollments- 0 .
[7] S. White and J. Tyler, Underrepresented Minorities in High School Physics: Results from the 2012-13 Nationwide Survey of High School Physics Teachers (American Institute of Physics, College Park, MD, 2015), https://www .aip.org/statistics/reports/underrepresented-minorities-highschool-physics.

[8] National Science Board, Science and Engineering Indicators 2018 (National Science Foundation, Alexandria, VA, 2018).

[9] A. M. Kelly and K. Sheppard, Secondary physics availability in an urban setting: Issues related to academic achievement and course offerings, Am. J. Phys. 77, 902 (2009).

[10] A. L. Griffith, Persistence of women and minorities in STEM field majors: Is it the school that matters?, Econ. Educ. Rev. 29, 911 (2010).

[11] S. White and C. L. Tesfaye, Nearly 1.4 million high school physics students-Enrollments in AP and second-year courses up $26 \%$ even though number of graduates down in 2012-13, Phys. Teach. 52, 276 (2014).

[12] S. White and J. Tyler, High School Physics Teacher Preparation: Results from the 2012-13 Nationwide Survey of High School Physics Teachers (American Institute of Physics, College Park, MD, 2015), https:// 
www.aip.org/statistics/reports/high-school-physics-teacherpreparation-0.

[13] U. S. Department of Education, Office of Civil Rights, STEM Course Taking (U. S. Department of Education, Washington, DC, 2018).

[14] A. M. Kelly and K. Sheppard, Access to elite urban science schools in the U.S.: Opportunity, disparate impact, and equal protection, Teachers College Record (2019), https:// www.tcrecord.org/Content.asp?ContentID=22951.

[15] L. Padwa, A. M. Kelly, and K. Sheppard, Chemistry teacher isolation, contextual characteristics, and student performance, J. Chem. Educ. 96, 2383 (2019).

[16] G. T. Rushton, D. Rosengrant, A. Dewar, L. Shah, H. E. Ray, K. Sheppard, and L. Watanabe, Towards a high quality high school workforce: A longitudinal, demographic analysis of U.S. public school physics teachers, Phys. Rev. Phys. Educ. Res. 13, 020122 (2017).

[17] K. Sheppard, L. Padwa, A. M. Kelly, and R. Krakehl, Outof-field teaching in chemistry and physics: An empirical census study, J. Sci. Teach. Educ. (to be published) https:// doi.org/10.1080/1046560X.2019.1702268.

[18] L. Darling-Hammond, Teacher quality and student achievement, Educ. Policy Analysis Archives 8, 1 (2000).

[19] S. White and J. Tyler, Who Teaches High School Physics? Results from the 2012-13 Nationwide Survey of High School Physics Teachers (American Institute of Physics, College Park, MD, 2014), https://www.aip.org/statistics/ reports/who-teaches-high-school-physics-0.

[20] C. L. Tesfaye and S. White, Challenges High School Teachers Face (American Institute of Physics, College Park, MD, 2012), https://www.aip.org/statistics/reports/ challenges-high-school-teachers-face.

[21] G. T. Henry, C. K. Fortner, and K. C. Bastian, The effects of experience and attrition for novice high-school science and mathematics teachers, Science 335, 1118 (2012).

[22] M. Dussault, C. Deaudelin, N. Royer, and J. Loiselle, Professional isolation and occupational stress in teachers, Psychological reports 84, 943 (1999).

[23] G. Nehmeh and A. M. Kelly, Urban science teachers in isolation: Challenges, resilience, and adaptive action, J. Sci. Teach. Educ. 29, 527 (2018).

[24] G. Borman and N. M. Dowling, Teacher attrition and retention: A meta-analytic and narrative review of the research, Rev. Educ. Res. 78, 367 (2008).

[25] M. F. Astiz, A. W. Wiseman, and D. B. Baker, Slouching towards decentralization: Consequences of globalization for curricular control in national education systems, Comp. Educ. Rev. 46, 66 (2002).

[26] E. Hirsch, J. Koppich, and M. Knapp, Revisiting What States Are Doing to Improve the Quality of Teaching: An Update on Patterns and Trends (Center for the Study of Teaching and Policy, University of Washington, Seattle, WA, 2001).

[27] R. M. Ingersoll and T. M. Smith, The wrong solution to the teacher shortage, Educ. Leadership 60, 30 (2003), http:// www.ascd.org/publications/educational-leadership/may03/ vol60/num08/The-Wrong-Solution-to-the-TeacherShortage.aspx.
[28] R. M. Ingersoll and T. M. Smith, Do teacher induction and mentoring matter?, NASSP Bulletin 88, 28 (2004).

[29] R. M. Ingersoll and D. Perda, Is the supply of mathematics and science teachers sufficient?, Am. Educ. Res. J. 47, 563 (2010).

[30] P. A. Alexander, The development of expertise: The journey from acclimation to proficiency. Am. Educ. Res. J. 32, 10 (2003).

[31] American Association for Employment in Education, Inc., Educator Supply and Demand Report 2015-16: Executive Summary (AAEE, Slippery Rock, PA, 2017).

[32] D. MacIsaac, J. Zawicki, D. Henry, D. Beery, and K. Falconer, A new model alternative certification program for high school physics teachers: New pathways to physics teacher certification at SUNY-Buffalo State College, J. Phys. Teach. Educ. Online 2, 9 (2004).

[33] C. J. Wenning, Repairing the Illinois high school physics teacher pipeline: Recruitment, preparation, and retention of high school physics teachers: The Illinois model, J. Phys. Teach. Educ. Online 2, 24 (2004).

[34] S. White and C. L. Tesfaye, High School Physics Availability: Results from the 2012-13 Nationwide Survey of High School Physics Teachers (American Institute of Physics, College Park, MD, 2014), https://www.aip.org/ statistics/reports/high-school-physics-availability-0.

[35] A. M. Kelly, Physics teachers' perspectives in factors that affect urban physics participation and accessibility, Phys. Rev. Phys. Educ. Res. 9, 010122 (2013).

[36] L. Merner and J. Tyler, African-American Participation Among Bachelors in the Physical Sciences and Engineering: Results from the 2005 to 2015 Data of the National Center for Education Statistics (American Institute of Physics, College Park, MD, 2019) https://www.aip.org/ statistics/reports/african-american-participation-amongbachelors-physical-sciences.

[37] L. Merner, Hispanic Participation Among Bachelors in Physical Sciences and Engineering: Results from the 2002 to 2012 Data of the National Center for Education Statistics (American Institute of Physics, College Park, MD, 2014) https://www.aip.org/statistics/reports/ hispanic-participation-in-physical-sciences-andengineering.

[38] American Institute of Physics, Race and Ethnicity of Physics PhDs, Classes of 2014 through 2016 (American Institute of Physics, College Park, MD, 2016) https://www .aip.org/statistics/data-graphics/race-and-ethnicityphysics-phds-classes-2014-through-2016.

[39] A. Burke, Science and Engineering Labor Force (National Center for Science and Engineering Statistics, National Science Board, Washington, DC, 2019) https://ncses.nsf .gov/pubs/nsb20198.

[40] National Center for Education Statistics, Status and Trends in the Education of Racial and Ethnic Minorities (National Center for Education Statistics, Institute for Education Sciences, Washington, DC, 2019) https://nces.ed.gov/ pubs2007/minoritytrends/.

[41] W. R. Shadish, T. D. Cook, and D. T. Campbell, Experimental and Quasi-Experimental Designs for Generalized Causal Inference (Houghton Mifflin, Boston, MA, 2002). 
[42] New York State Education Department, New York State Public School Enrollment (NYSED, Albany, NY, 2017), https://data.nysed.gov/enrollment.php?year=2017\&state=yes.

[43] ACT, The Condition of STEM 2013 New York (ACT, Iowa City, IA, 2014).

[44] New York State Education Department, Diploma Requirements (NYSED, Albany, NY, 2015), http://www.p12.nysed .gov/part100/pages/1005.html\#a.

[45] New York State Education Department, New York State Annual School Report Card Data, 2016-2017 (NYSED, Albany, NY, 2018), https://data.nysed.gov/reportcard.php? year $=2017 \&$ state $=$ yes.

[46] New York State Education Department, New York State Education Department Teacher Certification Look Up (NYSED, Albany, NY, 2019), https://eservices.nysed.gov/ teach/certhelp/CpPersonSearchExternal.jsp.

[47] National Center for Education and Statistics, Public Elementary/Secondary School Locale Code Files (U.S. Department of Education, Washington, DC, 2017) https:// nces.ed.gov/ccd/schoolsearch/.

[48] The University of the State of New York, Physical Setting/ Physics Core Curriculum (NYSED, Albany, NY, 2002), http://www.nysed.gov/common/nysed/files/programs/ curriculum-instruction/phycoresci.pdf.

[49] U. S. Department of Agriculture, National School Lunch Program Income Eligibility Guidelines (USDA Food and Nutrition Service, Washington, DC, 2017), https://www .fns.usda.gov/school-meals/income-eligibility-guidelines.

[50] College Board, AP Physics 1 Course and Exam Description (College Board, New York, NY, 2019).

[51] College Board, AP Physics 2 Course and Exam Description (College Board, New York, NY, 2019).

[52] College Board, AP Data-Archived Data 2017 (College Board, New York, NY, 2017).

[53] College Board, AP Physics C: Mechanics Course and Exam Description (College Board, New York, NY, 2019).

[54] College Board, AP Physics C: Electricity and Magnetism Course and Exam Description (College Board, New York, NY, 2019).

[55] R. M. Baron and D. A. Kenny, The moderator-mediator variable distinction in social psychological research: Conceptual, strategic, and statistical considerations, J. Personality Soc. Psychol. 51, 1173 (1986).

[56] E. S. Shernoff, A. M. Marínez-Lore, S. L. Frazier, L. J. Jakobsons, M. S. Atkins, and D. Bonner, Teachers supporting teachers in urban schools: What iterative research designs can teach us, School Psychol. Rev. 40, 465
(2011), https://www.tandfonline.com/doi/abs/10.1080/ 02796015.2011.12087525.

[57] J.S. Oliver, Rural science education, in Handbook of Research on Science Education, edited by S. K. Abell and N.G. Lederman (Routledge, London, UK, 2007), p. 345 .

[58] A. M. Kelly and K. Sheppard, The relationship between the small schools movement and access to physics education, Sci. Educat. 19, 14 (2010), https://eric.ed.gov/? $\mathrm{id}=$ EJ874150.

[59] A. M. Kelly and K. Sheppard, Newton in the big apple: Access to high school physics in New York City, Phys. Teach. 46, 280 (2008).

[60] E. H. Charron, Classroom and community influences on youths' perceptions of science in a rural county system, J. Res. Sci. Teach. 28, 671 (1991).

[61] W. E. Baird, J. P. Prather, K. D. Finson, and J. S. Oliver, Comparison of perceptions among rural versus nonrural secondary science teachers: A multistate survey, Sci. Educ. 78, 555 (1994).

[62] S. C. Lee, G. Nugent, G. M. Kunz, J. Houston, and S. DeChenne-Peters, Case study: Value-added benefit of distance-based instructional coaching on science teachers' inquiry instruction in rural schools, J. Sci. Teach. Educ. 29, 179 (2018).

[63] L. A. Annetta and J. A. Shymansky, Investigating science learning for rural elementary school teachers in a professional development project through three distanceeducation strategies, J. Res. Sci. Teach. 43, 1019 (2006).

[64] W. R. Penuel, W. Sussex, C. Korbak, and C. Hoadley, Investigating the potential of using social network analysis in educational evaluation, Am. J. Evaluation 27, 437 (2006).

[65] E. Etkina, B. Gregorcic, and S. Vokos, Organizing physics teacher professional education around productive habit development: A way to meet reform challenges, Phys. Rev. Phys. Educ. Res. 13, 010107 (2017).

[66] S. Vokos and T. Hodapp, Characteristics of thriving physics teacher education programs, in Recruiting and Educating Future Physics Teachers, edited by C. Sandifer and E. Brewe (American Physical Society, College Park, MD, 2015), p. 3.

[67] E. Etkina, Using early teaching experiences, and a professional community to prepare preservice teachers for everyday classroom challenges, to create habits of studentcentered instruction, and to prevent attrition, in Recruiting, and Educating Future Physics Teachers, edited by C. Sandifer and E. Brewe (American Physical Society, College Park, MD, 2015), p. 257. 